\title{
MORFOLOGIA E RESISTÊNCIA CICATRICIAIS DA PAREDE ABDOMINAL APÓS LAPAROTOMIAS LONGITUDINAL E TRANSVERSAL EM COELHOS
}

\author{
ABDOMINAL WALL MORPHOLOGY AND HEALING RESISTANCE AFTER \\ LONGITUDINAL AND TRANSVERSAL LAPARATOMY IN RABBITS
}

\author{
Mauro Ivan Salgado'; Andy Petroianu, TCBC- MG²; Giselle Lellis Burgarelli ${ }^{3}$; \\ Cristiana Buzelin Nunes ${ }^{4}$; Luiz Ronaldo Alberti5; Leonardo De Souza Vasconcellos ${ }^{6}$
}

\begin{abstract}
RESUMO: Objetivo: Foram estudadas comparativamente as laparotomias longitudinais paramediana e transversal avaliando-se a resistência cicatricial da parede abdominal e seu aspecto histológico, com peritônio suturado ou não. Método: 30 coelhos foram distribuídos em dois grupos: Grupo $1(\mathrm{n}=10)$ - laparotomia longitudinal, Subgrupo 1A $(\mathrm{n}=5)$ sutura das bainhas anterior e posterior do músculo reto abdominal, bem como do peritônio, Subgrupo 1B $(\mathrm{n}=5)$ sutura da bainha anterior do músculo reto abdominal. Grupo $2(\mathrm{n}=20)$ - laparotomia transversa, Subgrupo 2A $(\mathrm{n}=5)$ sutura das bainhas anterior e posterior do músculo reto abdominal, bem como do peritônio, Subgrupo 2B $(\mathrm{n}=5)$ sutura apenas da bainha anterior do músculo reto abdominal, Subgrupo 2C $(\mathrm{n}=5)$ sutura, em plano único, do músculo reto abdominal e de sua bainha anterior, Subgrupo 2D $(\mathrm{n}=5)$ síntese, da bainha posterior do músculo reto abdominal junto com o peritônio e, em seguida, sutura do músculo reto abdominal, complementada por sutura da bainha anterior desse músculo. Após 17 dias, foram retirados dois segmentos peritonio-aponeurotico-musculares da cicatriz para avaliação da resistência e de seus aspectos histológicos. Resultados: $\mathrm{O}$ valor da resistência para cada um dos grupos avaliados mostrou $1 \mathrm{~A}>1 \mathrm{~B}$, $1 \mathrm{~A}>2 \mathrm{~A}$ e $1 \mathrm{~B}>2 \mathrm{~B}$, e $2 \mathrm{~B}>2 \mathrm{C}>2 \mathrm{D}>2 \mathrm{~A}(\mathrm{p}=0,014)$. Deiscência, infecção e aderências foram mais freqüentes no Grupo 2 . A histologia mostrou degeneração e necrose muscular, com sua substituição por tecido conjuntivo fibroso maduro cicatricial. Conclusão: Esses dados indicam que o corte muscular transversal provoca maior enfraquecimento muscular e que o peritônio deixado aberto não altera a resistência cicatricial (Rev. Col. Bras. Cir. 2007; 34(4): 232-236).
\end{abstract}

Descritores: Cicatrização de feridas; Músculos; Laparotomia; Parede abdominal; Coelhos.

\section{INTRODUÇÃO}

A parede peritônio-aponeurotico-muscular abdominal é a via de acesso às vísceras abdominais para as diferentes operações laparotômicas. As laparotomias dividem-se em: longitudinais, que permitem acesso a todo o abdome, podendo ser mediana e paramedianas pararretal medial, transretal e pararretal lateral; e transversais, que seguem a orientação das linhas de força do abdome, perpendiculares ao plano sagital e podem seccionar o músculo reto do abdo$\mathrm{me}^{1,2}$.

Ainda não há consenso quanto ao melhor método de fechamento da parede abdominal. O mais usual é a sutura contínua, utilizando fio absorvível. Quando há risco de evisceração, em situações como obesidade, distensão abdominal e desnutrição, deve ser considerada a síntese total da parede, em um plano ${ }^{1,2}$.

A sutura peritoneal, obrigatória para muitos, previne aderências entre as vísceras e o restante da parede abdominal, além de reduzir o risco de infecção, e evisceração. Entretanto, essas vantagens não têm sido comprovadas em estudos experimentais ${ }^{3}$. Em contrapartida, algumas pesquisas mostraram que a sutura peritonial pode provocar isquemia, necrose e inflamação local, que retardariam a cicatrização e seriam causa de aderências. A reperitonização espontânea, quando não se sutura o peritônio, ocorre no período de 48 horas a seis dias ${ }^{4}$.

As freqüentes complicações decorrentes das vias de acesso ao abdome indicam a necessidade de se compreenderem melhor a estrutura e a função da parede abdominal. $\mathrm{O}$ presente trabalho, que faz parte de uma linha de pesquisa, teve como objetivos:

- comparar a morfologia e resistência da parede abdominal após diferentes laparotomias e sínteses;

-verificar a influência da síntese do peritônio na resistência cicatricial da parede abdominal e sua recuperação morfológica.

\footnotetext{
1. Mestre em Medicina; Professor Assistente do Departamento de Cirurgia da Faculdade de Medicina da UFMG.

2. Professor Titular do Departamento de Cirurgia da Faculdade de Medicina, UFMG; Docente-Livre de Técnica Operatória e Cirurgia Experimental da Escola Paulista de Medicina, UNIFESP; Docente-Livre de Gastroenterologia Cirúrgica da Faculdade de Medicina de Ribeirão Preto, USP; Doutor em Fisiologia e Farmacologia pelo Instituto de Ciências Biológicas, UFMG; Pesquisador IA do CNPq.

3. Médica.

4. Mestranda em Patologia da Faculdade de Medicina da UFMG; Patologista do Instituto Moacyr Junqueira e Santa Casa de Belo Horizonte.

5. Cirurgião Geral e Pediátrico; Mestre e Doutor em Cirurgia pela UFMG.

6. Mestre e Doutorando em Cirurgia da UFMG.
}

Recebido em 08/11/2006

Aceito para publicação em 09/01/2007

Conflito de interesses: nenhum

Fonte de financiamento: CNPq/FAPEMIG

Trabalho realizado no Departamento de Cirurgia da Faculdade de Medicina da Universidade Federal de Minas Gerais. 


\section{MÉTODO}

Este trabalho foi realizado no Laboratório de Cirurgia Experimental, de acordo com as recomendações das Normas Internacionais de Proteção aos Animais e do Código Brasileiro de Experimentação Animal (1988) e foi aprovado pelo Comitê de Ética em Experimentação Animal da Universidade Federal de Minas Gerais.

Foram estudados 40 coelhos (Oryctogalus cuniculus) da raça Nova Zelândia provenientes do Biotério Central da Escola de Veterinária UFMG, dez foram usados como piloto e os outros 30 foram distribuídos aleatoriamente em dois grupos. No início do experimento, todos os coelhos machos estavam com três meses de idade e peso médio de $3373 \pm 202 \mathrm{~g}$.

A anti-sepsia e a tricotomia de todos os animais foram feitas antes da anestesia.

Todos os coelhos foram anestesiados com cloridrato de quetamina em injeção intramuscular profunda no glúteo, na dose média de $3 \mathrm{ml}$ por coelho, $50 \mathrm{mg} / \mathrm{kg}$ peso. Em seguida, complementou-se a anestesia com cloridrato de lidocaína a $1 \%$ com vasoconstritor que foi injetada subcutânea e na bainha posterior do músculo reto abdominal, nos locais da operação antes de iniciar-se o procedimento.

Os animais foram distribuídos em:

- Grupo 1 ( $\mathrm{n}=10)$ : Laparotomia longitudinal, paramediana medial direita, em uma extensão de sete centímetros a partir do gradil costal direito.

- Subgrupo 1A $(n=5)$ - Síntese da bainha posterior do músculo reto abdominal junto com o peritônio e, em seguida, da bainha anterior desse músculo.

- Subgrupo 1B $(\mathrm{n}=5)$ - Síntese apenas da bainha anterior do músculo reto abdominal.

- Grupo $2(\mathrm{n}=20)$ : Laparotomia transversal a três centímetros do rebordo costal direito em uma extensão de sete centímetros a partir da linha alba.

- Subgrupo 2A $(n=5)$ - Síntese da bainha posterior do músculo reto abdominal juntamente com o peritônio e, em seguida, da bainha anterior desse músculo.

- Subgrupo 2B $(n=5)$ - Síntese somente da bainha anterior.

- Subgrupo 2C $(n=5)$ - Sutura, em plano único, do músculo reto abdominal e de sua bainha anterior.

- Subgrupo 2D $(n=5)$ - Síntese, da bainha posterior do músculo reto abdominal junto com o peritônio e, em seguida, sutura do músculo reto abdominal, complementada por sutura da bainha anterior desse músculo.

Em todos os animais, a síntese foi realizada com sutura contínua, utilizando fio de polipropileno monofilamento 3-0. Os planos de sutura seguiram a orientação do subgrupo ao qual o coelho pertencia. A sutura de pele incluiu o subcutâneo, usando o mesmo tipo de fio.

No $17^{\circ}$ dia pós-operatório, os animais foram mortos com injeção intramuscular de $3 \mathrm{ml}$ de cloridrato de quetamina. A seguir, foi realizada a retirada da parede abdominal com a cicatriz na sua parte média que permitiu a avaliação da integridade da cicatriz, focos sépticos, necrose, aderências, hérnias e eviscerações. Uma parte dessa estrutura, contendo a cicatriz foi separada para avaliação histológica. Do fragmento restan- te, foram confeccionadas dois segmentos de parede total $4 \times 1 \mathrm{~cm}$, contendo a cicatriz em sua parte média.

O segmento 1 retirado para histologia foi fixado em solução de Bouin, e processado secções de $5 \mathrm{~m}$ de espessura foram montadas em lâmina de vidro e coradas com HE, hematoxilina e eosina e tricrômico de Gomory. O exame foi realizado ao microscópio de luz, binocular. Ao exame microscópico, foi medida a espessura da área cicatricial e a da área adjacente normal da parede abdominal, usando uma lente milimetrada para ocular de microscópio óptico, com objetiva de 40 X. Essas medidas visavam a estabelecer o valor percentual de fibrose e cicatrização da ferida abdominal, além de avaliar a profundidade, largura e intensidades do exsudato inflamatório, bem como a neoformação vascular. A intensidade cicatricial foi denominada pequena quando houve menor concentração de células inflamatórias e vasos neoformados, moderada quando apresentou uma quantidade celular e neovascular intermediária, enquanto a intensidade grande foi considerada quando houve concentração maior celular e vascular.

Os testes de resistência foram realizados por duas pessoas: uma controlava o enchimento do frasco depósito, controlando a torneira, enquanto a outra segurava o frasco de plástico para evitar que o seu conteúdo se perdesse. Assim o conjunto a ser pesado mantinha-se sem alterações. Não ocorreu caso de queda ou perda de material examinado.

O segmento 2 foi submetido ao teste de resistência até sua ruptura. Esse segmento foi apreendido por duas pinças de Duval: a primeira foi fixada a um suporte metálico e suspendeu o segmento; a segunda pinça, colocada inferiormente, foi amarrada a um frasco de plástico com capacidade para cinco litros. Ambas as pinças foram colocadas à distância de um centímetro da cicatriz, em direção perpendicular a ela. Uma torneira do frasco-depósito de água destilada foi enchendo o frasco de plástico à velocidade de 1,5 litros/minuto até a ruptura do segmento contendo a cicatriz. No momento do rompimento, a torneira foi fechada. Pesou-se, em uma balança com capacidade para 25 gramas a $5 \mathrm{~kg}$, a água contida no frasco, acrescida do peso de parte do segmento rompido, a pinça de Duval inferior, o barbante e o próprio frasco de plástico. A soma desses pesos representou a força de ruptura do tecido e, conseqüentemente, sua resistência. Quando o rompimento ocorreu na cicatriz, considerou-se o dado como resistência cicatricial. Nos casos em que o rompimento foi próximo à cicatriz, a resistência cicatricial foi maior do que a do tecido circunjacente.

As comparações entre os seis subgrupos estudados quanto às medidas das variáveis, músculo íntegro, altura e largura da cicatriz, área da cicatriz, pesos inicial e final dos coelhos, bem como a resistência da cicatriz, foram realizadas utilizando o teste não paramétrico de Kruskal-Wallis. Utilizouse também, o teste exato de Fisher nos casos que romperam na cicatriz ou fora dela, independentemente do tipo de laparorrafia. Foi utilizado o teste de Wilcoxon para comparar, o peso inicial e o final de um mesmo coelho, avaliando o mesmo fenômeno em dois momentos diferentes.

Todos os resultados foram considerados significativos ao nível de significância de $5 \%(\mathrm{p}<0,05)$, tendo, portanto, $95 \%$ de confiança. 


\section{RESULTADOS}

Em relação ao peso dos coelhos, houve variação entre o início e o fim do experimento. O peso final dos animais foi menor que o seu peso no início do estudo, provavelmente em decorrência da resposta sistêmicas às operações realizadas.

Nos animais do Grupo 1, após 17 dias, não foi observada deiscência na cicatriz cirúrgica de pele. Houve infecção de parede abdominal em dois casos que apresentaram pequenas lesões nodulares brancacentas, com conteúdo caseoso, sem fístula ou exsudato purulento. Foram encontradas aderências intra-abdominais em dois animais. No Grupo 2, quatro coelhos dentre os 20 operados tiveram deiscência na cicatriz cirúrgica de pele e cinco coelhos, infecção de parede. A infecção tinha aspecto idêntico à do Grupo 1 e pequeno nódulo caseoso ulcerado ou entumescido, com bordas elevadas e irregulares. Em 14 coelhos foram encontradas aderências à parede abdominal de omento maior $(\mathrm{n}=10)$, intestino delgado $(\mathrm{n}=2)$ e múltiplas vísceras $(\mathrm{n}=2)$.

A resistência da cicatrização peritônio-aponeuroticomuscular avaliada após 17 dias nos subgrupos da incisão longitudinal, 1A e 1B, foi superior à encontrada nas cicatrizes das incisões transversais do Grupo $2(\mathrm{p}=0,014$ Teste de Kruskal Wallis). O valor da resistência muscular para cada um dos subgrupos foi. No Grupo 1, da laparotomia longitudinal, 60\% dos segmentos de parede romperam fora da cicatriz. Em 40\% dos coelhos, a ruptura ocorreu no local da cicatriz. (Figura 1)

Quanto ao local de rompimento, no Grupo 2, 90\% romperam no local em que o músculo reto abdominal foi seccionado transversalmente. Somente em 10\% dos coelhos, o rompimento ocorreu fora da cicatriz na parede abdominal, independentemente do tipo de laparorrafia.

No Grupo 1 (medida média da cicatriz de 5,10 $\pm 1,40$ $\mathrm{mm}$ de espessura por $10 \pm 5,20 \mathrm{~mm}$ de largura) a área de cicatrização foi em média mais larga e menos espessa do que no Grupo 2 ( 5,58 $\pm 1,25 \mathrm{~mm}$ de espessura por 9,43 $\pm 3,45 \mathrm{~mm}$ de largura). Nas cicatrizes de todos os animais houve degeneração do músculo esquelético no local da secção cirúrgica, com substituição muscular por tecido conjuntivo fibroso cicatricial maduro, cuja intensidade variou de acordo com o tipo de secção muscular. Nos dois grupos ocorreu neoformação vascular e infiltrado inflamatório mononuclear de pequena ou moderada intensidade, predominando linfócitos e histiócitos. (Figura 2)

Nas cicatrizes dos dois grupos foram encontrados também focos de inflamação aguda com necrose e exsudato purulento. No Grupo 2, o número de animais com essa complicação foi maior ( 11 casos ou 55\% no Grupo 2 e 5 casos ou 50\% no Grupo 1$)(p=0,07)$. Já a reação inflamatória $(p=0,339)$ e a neoformação vascular $(\mathrm{p}=0,384)$ foram mais intensas no Grupo 2 , que também teve retardo no processo cicatricial. Segmentos de fio cirúrgico foram encontrados ainda nas amostras, apesar de terem sido removidos antes da secção histológica.

\section{DISCUSSÃO}

O estudo da musculatura da parede abdominal é importante para compreenderem-se e eventualmente preveniremse as principais complicações das cirurgias abdominais, como eventrações e eviscerações, além de ampliar possibilidades do uso de incisões combinadas ${ }^{14} \mathrm{em}$ casos de necessidade ${ }^{5,6}$.

Nesta pesquisa, optou-se pelo coelho de três meses de idade e peso superior a três quilogramas, pela facilidade de manuseio, nutrição e cuidados, e estrutura musculoaponeurótica e peritoneal, muito delgada, mas similar à de outros mamíferos, incluindo o homem.

Investigações prévias desta linha de pesquisa sobre cicatrização ${ }^{7-11}$ e o estudo piloto orientaram a escolha de 17 dias para o período de acompanhamento dos animais.
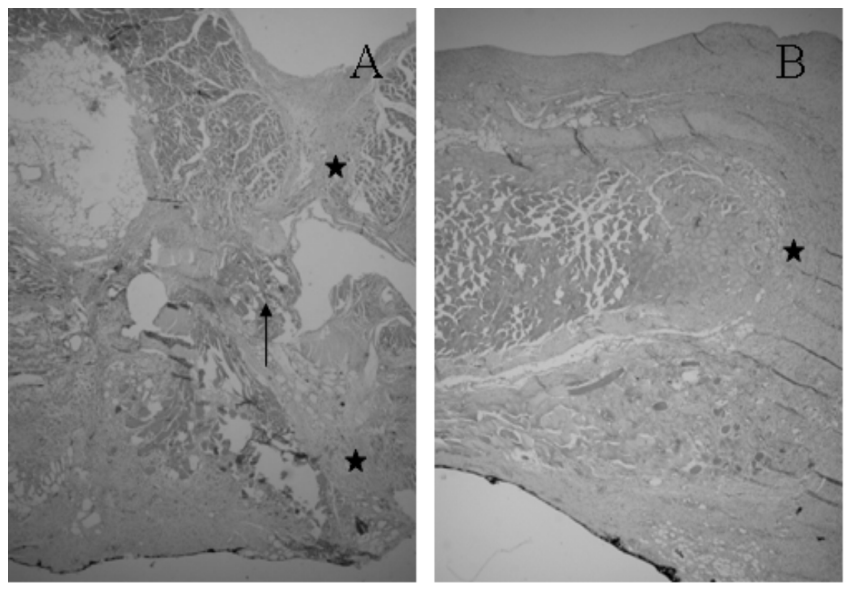

Figura 2-Cortes histológicos de parede abdominal:

A-Grupo 1 A: Fibrose cicatricial estreita, com pequena retração da bainha externa (*), associada a infiltrado inflamatório mononuclear moderado e pequena neoformação vascular (seta), em toda espessura da parede abdominal (Coelho 1A-2 - HE 25 X).

$B$ - Grupo 2B: Fibrose cicatricial (*) com aumento total de sua espessura em toda a parede abdominal (Coelho 2B-1 - HE 25 X). 
Dentre as laparotomias, as longitudinais são mais realizadas pela facilidade técnica e rapidez com que podem ser executadas, além da possibilidade de inventário e manuseio dos órgãos intra-abdominais, mas há relatos de elas serem acompanhadas de mais complicações, principalmente se forem infra-umbilicais. Por outro lado, as laparotomias transversais são menos realizadas devido ao maior tempo cirúrgico para sua execução e menor campo de ação intra-abdominal $5,6,12-15$.

O exame histológico com as duas colorações (hematoxilina e eosina, e tricrômico de Gomori) permitiu maior acuidade nos exames. Em algumas lâminas foi bem evidente a retração muscular, principalmente na laparotomia longitudinal. As laparotomias transversais apresentaram maior fibrose, provavelmente pela resposta orgânica mais intensa, em virtude da secção muscular.

Neste trabalho, as suturas ocorreram em planos superpostos, com maior ajuste da área operada. Contudo, os resultados obtidos não permitem afirmar que o peritônio deixado aberto ou suturado tenha influenciado na resistência da cicatriz da parede abdominal nem que tenha havido melhor recuperação muscular. Com o peritônio aberto ocorre a aproximação natural de suas bordas e as vísceras intra-abdominais recobrem a área cruenta aumentando as aderências. Esse processo promove a recuperação completa da integridade peritoneal. Com o tempo, algumas aderências se desfazem ${ }^{3-}$ $5,16-22$.

O rompimento da parede abdominal na cicatriz indica ter sido essa a parte mais fraca, fato esse esperável pelo teste realizar-se ainda na fase de recuperação tecidual. Cabe, entretanto, ressaltar que, em alguns casos, a cicatriz foi mais resistente do que a parede normal, fato esse que indica a importância dos fenômenos envolvidos na cicatrização. Na maioria dos casos de laparotomia longitudinal a ruptura ocorreu fora da cicatriz, enquanto que nas laparotomias transversas a ferida cirúrgica foi o local em que se deu o rompimento. Talvez uma explicação para essa diferença de resistências das cicatrizes em relação à sua direção seja decorrente da disposição das fibras colágenas, que são a base que orienta a recuperação tecidual.

Embora a laparotomia transversa seja considerada mais fisiológica, neste estudo todos os resultados foram melhores na laparotomia longitudinal. Mesmo com a extensa revisão bibliográfica feita, não foi possível encontrar explicação para a diversidade de respostas individuais da parede abdominal ao trauma cirúrgico.

De um modo geral, a capacidade de regeneração muscular é baixa, e o processo cicatricial incompleto com fibrose em toda extensão da cicatriz ${ }^{23-28}$. Nas condições deste trabalho o músculo não se recuperou e foi substituído por fibrose. A baixa ocorrência de deiscência e infecção superficial não influenciou nos resultados do teste de resistência da parede abdominal. Manter o peritônio aberto não mostrou inconveniência neste estudo, tendo em vista que não foi verificada complicação decorrente dessa conduta.

Concluindo, consideramos pertinente afirmar que, nas condições experimentais deste trabalho, as laparotomias longitudinais foram mais resistentes do que as transversais e que o peritônio pouco interfere na resistência cicatricial da parede abdominal. A cicatrização do músculo reto abdominal após diferentes laparotomias e sínteses não apresenta diferenças em sua recuperação morfológica. Não há evidência de que o peritônio afete a resistência cicatricial da parede abdominal ou em sua recuperação morfológica.

\section{AGRADECIMENTOS}

Os autores agradecem ao CNPq e à FAPEMIG pelos auxílios financeiros que permitiram a realização deste trabalho.

\begin{abstract}
Background: The abdominal wall is a main topic of investigation in terms of its healing. The purpose of this investigation was to assess the healing of transverse and longitudinal laparotomies. Methods: Thirty rabbits were distributed into two groups: Group $1(n=10)$ longitudinal laparotomy, Subgroup $1 \mathrm{~A}(n=5)$ suture of the anterior and posterior sheaths of the abdominal rectal muscle and peritoneum, Subgroup $1 B(n=5)$ suture of the anterior abdominal rectal muscle sheath. Group $2(n=20)$ transverse laparotomy, Subgroup $2 A(n=5)$ suture of the anterior and posterior sheaths of the rectal muscle and peritoneum, Subgroup $2 B(n=5)$ suture of only the anterior rectal muscle sheath, Subgroup $2 C(n=5)$ suture of the anterior rectal muscle sheath of the, Subgroup $2 D(n=5)$ suture of the anterior and posterior rectal muscle sheaths, including the peritoneum. After 17 days, two peritoneal-aponeurotic-muscle segments with the scar were removed in order to verify their resistance and histological aspects. Results: The resistance values detected on each group showed $1 A>1 B, 1 A>2 A$ and $1 B>2 B$, and $2 B>2 C>2 D>2 A(p=0.014)$. Dehiscence, infections and adhesions were more frequent in Group 2. Histology revealed muscle degeneration and necrosis, with mature fibrous connective scar tissue replacing the muscle. Conclusion: Transverse muscle section provokes a greater muscle weakening; the peritoneum closure does not modify the scar resistance.
\end{abstract}

Key words: Wound healing; Muscles; Laparotomy; Abdominal wall; Rabbits.

\section{REFERÊNCIAS}

1 Borud LJ, Grunwaldt L, Janz B, Mun E, Slavin SA. Components separation combined with abdominal wall plication for repair of large abdominal wall hernias following bariatric surgery. Plast Reconstr Surg. 2007; 119(6):1792-8.

2 Davies M, Davies C, Morris-Stiff G, Shute K. Emergency presentation of abdominal hernias: outcome and reasons for delay 
in treatment - a prospective study. Ann R Coll Surg Engl. 2007; 89(1):47-50.

3 Ellis H, Heddle R. Does the peritoneum need to be closed at laparotomy? Br J Surg. 1977; 64(10):733-6.

4 Liakakos T, Thomakos N, Fine PM, Dervenis C, Young RL. Peritoneal adhesions: etiology, pathophysiology, and clinical significance. Recent advances in prevention and management. Dig Surg. 2001; 18(4): 260-73.

5 Berney T, Morel P, Huber O, Zurbuchen P, Mentha G. Combined midline-transverse surgical approach for severe blunt injuries to the right liver. J Trauma. 2000; 48(2):349-53.

6 Tekkis PP, Krysa J, Chan S, Challiner A, South LM, Andrews SM. Randomized prospective comparison of postoperative pain control and respiratory complications following midline or transverse laparotomy for aortic surgery. Br J Surg. 2001; 88(4): 611-2.

7 Melo MAB, Almeida LM, Barbosa AJA, Petroianu A. Cicatrização de anastomose colônica em ratos submetidos a diferentes preparos colônicos. Rev Bras Colo-Proct. 1996; 16(1):19-22.

8 Petroianu A, Carvalho LB, Rocha KD, Barbosa AJA. Prevention of abdominal adhesions does not interfere with jejunal anastomosis healing. Int J Surg Invest. 1999; 1(2):149-56.

9 Petroianu A, Souza SD, Martins SG, Alberti LR. Influência do ácido ascórbico em anastomoses e alças jejunais íntegras de rato. Arq Gastroenterol. 2001; 38(1): 48-52.

10 Salgado MI. Estudo comparativo de cicatrização conduzida e enxerto de pele para tratamento de área cruenta cutânea, em coelhos [dissertação]. Belo Horizonte (MG): Universidade Federal de Minas Gerais; 2004.

11 Souza AA, Petroianu A, Trapiello Neto V, Rios VS, Barbosa AJA. Effect of sodium carboxymethylcellulose and methylprednisolone on the healing of jejunal anastomoses in rats. Braz J Med Biol Res. 2001; 34(4):519-23.

12 Fejtek M, Wassersug R. Effects of laparotomy, cage type, gestation, period and spaceflight on abdominal muscles of pregnant rodents. J Exp Zool. 1999; 284(3):252-64.

13 Foschi D, Corsi F, Cellerino P, Rizzi A, Morandi E, Trabucchi E. Angiogenic effects of suture biomaterials. An experimental study in rats. Eur Surg Res. 2001; 33(1):16-20.

14 Höeer J, Anurov M, Titkova S, Klinge U, Töns C, Ottinger A, Schumpelick V. Influence of suture material and suture technique on collagen fibril diameters in midline laparotomies. Eur Surg Res. 2000; 32(6):359-67.

15 Höer J, Klinge U, Schachtrupp A, Töns C, Schumpelick V. Influence of suture technique on laparotomy wound healing: an experimental study in the rat. Langenbecks Arch Surg. 2001; 386(3):218-23.

16 Yee SS, Medina VEA, Cabrera MB, Justo RI. Efecto de la sutura peritoneal en la formación de adherencias post-operatorias. Estudio experimental en ratas. Cir Gen. 2001; 24(1):22-7.

17 Israelsson LA. The surgeon as a risk factor for complications of midline incisions. Eur J Surg. 1998; 164(5):353-9.
18 Niggebrugge A, Arthur HP, Trimbos JB, Hermans J, Steup WH, Van De Velde CJ. Influence of abdominal-wound closure technique on complications after surgery: a randomised study. Lancet. 1999; 353(9164):1563-7.

19 Gonçalves RM, Esquerdo CRM, Petroianu A, Barbosa AJA. Influência de aderências peritoneais e fio cirúrgico na tensão de ruptura da parede abdominal em ratos. Rev Col Bras Cir. 2000; 27(3):147-52.

20 Petroianu A, Souza SD, Martins SG, Alberti LR, Vasconcellos LS. Influência da vitamina $\mathrm{C}$ e da hidrocortisona sobre a tensão anastomótica jejunal em ratos. Acta Cir Bras. 2000; 15(4):215-9.

21 Petroianu A, Cavalcanti AMT, Alberti LR. Efeito da hidrocortisona sobre a pressão de ruptura dos diversos segmentos do tubo digestório de camundongo. An Fac Med Univ Fed Pernambuco. 2002; 47(2):112-5.

22 Vasconcellos LS, Alberti LR, Nunes CB, Petroianu A. Efeito da hidrocortisona sobre a resistência cicatricial da pele em camondongos. Rev Col Bras Cir. 2001; 28(6):438-43.

23 Chan YS, Li Y, Foster W, Fu FH, Huard J. The use of suramin, an antifibrotic agent, to improve muscle recovery after strain injury. Am J Sports Med. 2005; 33(1):43-51.

24 Foster W, Li Y, Usas A, Somogyi G, Huard J. Gamma interferon as an antifibrosis agent in skeletal muscle. J Orthopaed Res. 2003; 21(5):798-804.

25 Fukushima K, Badlani N, Usas A, Riano F, Fu F, Huard J. The use of an antifibrosis agent to improve muscle recovery after laceration. Am J Sports Med. 2001; 29(4):394-402. Erratum in: Am J Sports Med. 2006; 34(1):146. Dosage error in text.

26 Huard J, Li Y, Fu FH. Muscle injuries and repair: current trends in research. J Bone Joint Surg Am. 2002; 84-A(5):822-32.

27 Kasemkijwattana C, Menetrey J, Bosch P, Somogyi G, Moreland MS, Fu FH, Buranapanitkit B, Watkins SS, Huard J. Use of growth factors to improve muscle healing after strain injury. Clin Orthop Relat Res. 2000; (370):272-85.

28 Li Y, Foster W, Deasy BM, Chan Y, Prisk V, Tang Y, Cummins J, Huard J. Transforming growth factor-beta 1 induces the differentiation of myogenic cells into fibrotic cells in injured skeletal muscle: a key event in muscle fibrogenesis. Am J Pathol. 2004; 164(3):1007-19.

Como citar este artigo:

Salgado MI, Petroianu A, Burgarelli GL, Nunes CB, Alberti LR, Vasconcellos LS. Morfologia e resistência cicatriciais da parede abdominal após laparotomias longitudinal e transversal em coelhos. Rev Col Bras Cir. 2007;34(4). Disponível em URL: www.scielo.br/rcbc

Endereço para correspondência:

Prof. Andy Petroianu

Av. Afonso Pena, no 1626, Apto 1901.

30130-005 - Belo Horizonte, MG

Fone/Fax: (31) 3274-7744

E-mail: petroian@medicina.ufmg.br 